\title{
20 Years of Exclusive Leadership Education Celebrated at Johnson \& Johnson-Wharton Fellows Program in Management for Nurse Executives
}

For the past $\mathbf{2 0}$ years, some of the world's top nurses have competed to participate in The Johnson \& Johnson-Wharton Fellows Program in Management for Nurse Executives (www.nursefellows.net). For three weeks each year, an international group of vice presidents of patient care and/or chief nurse executives have the opportunity to study strategic, financial, managerial and leadership approaches to organizational development at the renowned Wharton School of the University of Pennsylvania. This initiative was the first to provide this type of education for senior nurse executives and is widely regarded as the leading program of its kind.

Each year, there is an abundant number of applicants from the United States, Asia and Europe for the 40 spots in the program. On average, two to five candidates are accepted from Canada, a number that should increase, according to Jim Irving, National Executive Business Director, J\&J Medical Products Canada. He encourages senior nurse executives to apply, saying, "The more Canadian nurse executives who become Wharton Fellows the better for our Canadian healthcare system".

Given that past fellows all began their careers in hand's-on patient care, it's no surprise that participants incorporate newly acquired leadership skills into a pre-existing commitment to patient care. As senior managers in their respective health centres, they fulfill nursing leadership roles with expertise and confidence, reinforcing their place at the management table. It's J\&J's belief that patient care suffers with any reduction in nursing leadership, ergo, the company's continued financial commitment to ensuring nurses' credibility at the table.

Developed by Wharton faculty under guidance from an expert advisory committee, the program is updated yearly to reflect the latest approaches in management education, applied to current healthcare issues. The Wharton selection committee chooses applicants according to strict criteria which includes that the applicant report directly to the CEO or COO and that the hospital or alliance be a major entity. As the oldest collegiate business school in the United States, Wharton is recognized worldwide for innovative leadership, academic strength and its impact on management. The Leonard Davis Institute of Health Economics, a cooperative venture of medicine, business, nursing and dental medicine, is the primary location of activities in health services research and education.

The nurse executive curriculum offers conceptual frameworks for leaders to shape their organization to meet the demands of a changing healthcare environment, including learning specific approaches to systems thinking, leading organizational change, negotiation strategies, marketing and consumer satisfaction. Current healthcare data and computer simulations incorporate management theory with highly interactive sessions. One novel aspect is when the participant's CEO or $\mathrm{COO}$ joins the program for a three-day Executive Forum. This signifies the seriousness of the organization's commitment to securing the participant's place at the decision-making table and provides an opportunity for them to apply key concepts in their own organization. It also gives senior executives time to apply what they've learned and to define follow-up actions that no management meeting or chat in the hallway could possibly allow.

Past participants range from Providence Health Care in British Columbia to the Health Care Corporation of St. John's in Newfoundland. Representatives include a dozen Ontario health centres, along with The Calgary Regional Health Authority in Alberta, Queen Elizabeth II Health Sciences Centre in Nova Scotia and the Royal Victoria Hospital and McGill University Health Centre in Quebec.

For alumni fellows, the program holds an annual refresher to keep enthusiasm strong. Typically, 100 nurse executives attend, with perhaps five being Canadian. "I try to keep Canadian alumni fellows in contact with each other via many different ways, from area dinners to joint sponsorships at nursing leadership conferences," says Irving. Given today's climate and assurance of constant change, the patient care focus is one program priority that remains constant.

The next session will be held June 1-20,2003 in Philadelphia, Pennsylvania with the CEO/COO Executive Forum on June 17-20. Application deadline January 31. www.nursefellows.net. 